\title{
Avaliação do plantão psicológico de um serviço-escola de Psicologia
}

\author{
Maria Lúcia Mantovanelli Ortolan \\ Maíra Bonafé Sei
}

\section{RESUMO}

O Plantão Psicológico é um serviço de caráter emergencial que objetiva acolher a experiência da pessoa em urgência psicológica, por meio de um encontro único. Objetivou-se, assim, compreender a visão dos usuários acerca do atendimento psicológico prestado em modalidade de plantão psicológico em um serviço-escola de Psicologia, por meio de um estudo qualitativo. Participaram da pesquisa seis usuários do serviço atendidos entre setembro de 2015 a janeiro de 2016. A partir da entrevista estruturada realizada com os participantes, foram criadas oito categorias de análise: a) o caráter emergencial e a necessidade da fala, b) expectativas direcionadas ao serviço psicológico, c) acolhimento, d) efeitos do encontro, e) competências do plantonista, f) vínculo terapêutico na instituição, g) pontos positivos do serviço e h) pontos negativos do serviço. Há uma satisfação dos participantes em relação ao acolhimento por parte do plantonista, rapidez no atendimento e bem-estar proporcionado pela conversa tida no plantão. Sugere-se mais pesquisas de avaliação para que profissionais programem ações na saúde mais específicas para população atendida.

Palavras-chave: plantão psicológico; clínicas-escola; saúde mental; follow-up.

\section{ABSTRACT}

\section{Evaluation of the psychological duty of a psychology school clinic}

The psychological duty is an emergency service that aims to welcome the person's experience in psychological urgency through a unique encounter. The purpose of this study was to understand the users' perception about the psychological care provided in the psychological duty in a psychology school clinic through a qualitative study. Six users of the service attended between September 2015 and January 2016 participated in the research. From the structured interview conducted with the participants, eight categories of analysis were created: a) the emergency character and the need for talking, b) expectations directed to the psychological service, c) reception, d) effects of the consultation, e) the skills of the attendant, f) therapeutic link with the institution, $g$ ) positive points of the service and $h$ ) negative points of the service. There is a satisfaction of the participants regarding the reception by the attendant, quickness in the care and well-being provided by the conversation on the psychological duty. More evaluation research is suggested for professionals regarding more specific program health actions to the population served.

Keywords: psychological duty; school clinics; mental health; follow-up.

O Plantão Psicológico aqui investigado é ofertado por meio de um projeto de extensão da universidade que tem como objetivo atender pessoas em emergência psicológica que tenham buscado o serviço espontaneamente ou que foram encaminhadas por outros serviços da rede de saúde mental e assistência social. Trata-se de uma modalidade de atendimento, oferecida de modo constante e estável, que se configura como um espaço de acolhimento e escuta dos sujeitos em sofrimento urgente. Em encontros únicos, os plantonistas objetivam junto com o usuário em crise clarificar a demanda deste. Esse modelo de acolhimento psicológico é inspirado nas walk-in clinics americanas, que chegaram ao Brasil mais conhecidos como

\section{Sobre os Autores}

M. L. M. O

orcid.org/0000-0002-9489-5823

Universidade Estadual de Londrina (UEL) - Londrina, PR ortolan78@gmail.com

M. B. S.

orcid.org/0000-0003-0693-5029

Universidade Estadual de

Londrina (UEL) - Londrina, PR

mairabonafe@gmail.com

\section{Direitos Autorais}

Este é um artigo de acesso aberto e pode ser reproduzido livremente, distribuído,

transmitido ou modificado, por qualquer pessoa desde que usado sem fins comerciais. 0 trabalho é disponibilizado sob a licença Creative Commons CCBY-NC.

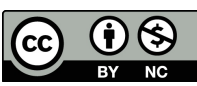




\section{WIINTERACÃO EM ET. PSICOLOGIA}

serviço de Pronto Atendimento Psicológico (Mozena, 2009; Slive \& Bobele, 2012).

Encontra-se a modalidade de plantão psicológico em diferentes contextos, com diversas metodologias e abordagens. Nas universidades (Rosario \& Neto, 2016), em escolas (Szymanski, 2004; Campos \& Cury, 2009), em espaços de saúde pública como Unidades Básicas de Saúde (Amorim, Andrade, \& Branco, 2015), no contexto da assistência social, como Centros de Referência (Mota \& Goto, 2009) e instituições de longa permanência para idosos (Ramos, 2012). Na área judiciária também se encontram atendimentos psicológicos em forma de plantão, como em serviços-escola de assistência jurídica (Mozena, 2009), na Delegacia da Mulher (Farinha \& Souza, 2016), no sistema penitenciário feminino (Guedes, 2006), no distrito policial (Braga, Mosqueira \& Morato, 2012) e em unidades de internação para adolescentes em conflito com a lei (Aun, Morato, Noguchi, \& Nunes, 2006). Outros espaços menos ortodoxos também subsidiam a prática de plantão, tais como ONGs (Rasera \& Issa, 2007), terreiros de umbanda (ScorsoliniComin, 2014) e favelas (Coin-Carvalho \& Ostronoff, 2014). Observa-se que, independentemente da metodologia e contexto empregados, a maior expressão da produção científica sobre plantão envolve a abordagem fenomenológico-existencia I(Scorsolini-Comin, 2015).

Tendo em vista o plantão aqui estudado, ofertado no serviço-escola de Psicologia de uma universidade pública, observa-se o quanto esse tipo de intervenção clínicas se apresenta como um serviço que pode integrar a Rede de Atenção à Saúde Mental e de Assistência Social. Nesse caso, promove-se uma rede solidária de recursos na saúde mental (Schimidt, 2006) estreitando laços entre futuros profissionais e os serviços disponíveis na rede, uma vez que os plantonistas buscam parcerias com os serviços públicos (Furigo, Sampedro, Zanelato, Foloni, Ballalai e Ormrod, 2008). Esses laços só são possíveis na medida em que o psicólogo ganha espaço nas políticas públicas (Vieira \& Boris, 2012) principalmente na Atenção Básica. Todavia, o cotidiano do serviço de plantão vem denunciando uma falta de diálogo entre os serviços de saúde, tanto internos quanto externos à universidade. E mais além da falta de diálogo entre os pontos da rede, evidencia-se uma frágil organização (tanto nos âmbitos de informatização e documentação dos atendimentos quanto nas práticas e ações realizadas) dos serviços públicos em saúde, principalmente a saúde mental. Sabe-se que essa dificuldade de criar um sistema de informação que funcione acarreta em prejuízo para a população alvo desses serviços (Laguardia, Domingues, Carvalho, Lauerman, Macário e Glatt, 2004; Hoffmann, Santos, \& Mota, 2008).
O projeto de extensão que oferta o plantão psicológico, preocupando-se com essas questões, começou a criar um sistema de informação sobre esse serviço, uma vez que em pesquisas anteriores foi feita a caracterização dos usuários do serviço a fim de repensar as práticas diárias e verificar possíveis mudanças que devam ser feitas de acordo com o perfil do usuário que o plantão recebe. Desse modo, junto com a caracterização dos usuários do plantão, a análise do serviço por meio da compreensão do ponto de vista dos usuários auxilia nesta tarefa de tornar o serviço mais efetivo e adequado à realidade da população ali atendida.

A pesquisa qualitativa que subsidia a análise crítica dos serviços prestados, a partir do ponto de vista de seus usuários, é justificada e relevante à medida que "permite aferir a adequaçãodos recursos disponíveis para o atendimento às reais necessidades do usuário" (Almeida \& Melo-Silva, 2006, p. 82). Defende-se o uso de um delineamento metodológico qualitativo nessas pesquisas, pois assim pode ser considerado de maneira integrada os resultados e processos do atendimento psicológico recebido e considera os fatores intrapessoais do usuário e fatores do contexto - a instituição, o terapeuta, dentre outros (French, Hiebert, \& Bezanzon, 1994).

Não há muitas publicações acadêmicas que relatem os estudos qualitativos de análise dos serviços de saúde mental a partir da compreensão da visão do usuário (Santeiro, 2008), principalmente em avaliação de serviço de plantão psicológico. Pan, Zonta e Tovar (2015) discorrem sobre a implantação do Plantão Institucional, prática inserida na Universidade Federal do Paraná e destinada ao acolhimento aos estudantes da universidade por meio de Entrevistas de Acolhimento. Avaliaram a prática empreendida por meio de entrevistas individuais realizadas por telefone ou presencialmente, observando-se uma avaliação positiva que apontou um processo de ressignificar a queixa. Consideraram ter havido um reconhecimento, um apoio e um processo de orientação às necessidades dos estudantes atendidos, contemplando sua dimensão emocional (Pan et al., 2015). Ao analisar a visão do usuário de um serviço, há a possibilidade de reconhecer o impacto deste na vida do sujeito e, a partir disso, pode-se avaliar se o atendimento prestado possui benefícios junto ao público atendido, assim como permite mapear as fragilidades existentes a fim de corrigi-las visando um atendimento cada vez mais próximo das reais necessidades do usuário (Almeida \& Melo-Silva, 2006). De acordo com o que foi apontado até aqui, esta pesquisa almejou, então, compreender a visão dos usuários acerca do atendimento psicológico prestado em modalidade de plantão psicológico em um serviço-escola de Psicologia por meio de uma pesquisa qualitativa, com entrevistas de usuários já atendidos no serviço. Com os feedbacks coletados na 


\section{W INERACÄOEM ET. PSICOLOGIA}

pesquisa, espera-se repensar as práticas do serviço a fim de sistematizar melhorias necessárias à população atendida.

\section{MÉTODO}

Esta foi uma pesquisa qualitativa, na qual a coleta de dados ocorreu por meio de entrevistas com um roteiro estruturado visando a compreensão dos usuários acerca de um serviço em saúde mental. Neste estudo, a escolha do método de pesquisa qualitativa foi relevante pelo seu caráter exploratório que estimula os entrevistados a pensarem livremente a respeito dos efeitos consequentes do atendimento no Plantão Psicológico, permitindo que eles relatem de forma espontânea suas experiências e avaliações do serviço. A pesquisa qualitativa por meio de entrevista com perguntas norteadoras facilita ao pesquisador compreender de maneira mais profunda e significativa as questões levantadas pelos participantes (Silva, Bastos \& Silva, 2017). Outro fator que contribuiu para a escolha do método qualitativo foi o fato da temática "promoção em saúde mental" não ser mensurável apenas quantitativamente (Minayo, 2004). Ressalta-se que esta pesquisa entrevistou os usuários atendidos em plantão de acordo com o parecer do comitê de ética do setor de saúde da Universidade Estadual de Londrina, CAAE 59846516.3.0000.5231, parecer 1.816.260.

\section{PARTICIPANTES}

O contato com os participantes foi feito por meio de ligações. Telefonou-se para 68 usuários que foram atendidos no Plantão Psicológico nos meses de setembro de 2015 a janeiro de 2016. Dos 68 usuários, 24 não foram encontrados considerou-se que, após três telefonemas, em horários e dias alternados, desistir-se-ia de entrar em contato. Tendo em vista os critérios de exclusão apresentados a seguir, 20 usuários foram excluídos da pesquisa: a) os que estavam com as suas respectivas fichas não preenchidas corretamente; b) os atendidos em plantão pela pesquisadora; c) aqueles que não tiveram interesse em participar; d) os que estavam internados ou impossibilitados de se deslocarem até o local da entrevista ou de receber a pesquisadora em algum local; e) os que tinham como sintomática a perda de memória e/ou dificuldade na fala; f) os que haviam comparecido mais de uma vez no plantão. Ainda, treze usuários recusaram-se a participar da pesquisa e cinco não compareceram à entrevista marcada.

Por fim, apenas seis usuários foram entrevistados, todas mulheres: P01, 41 anos, foi atendida no plantão em dezembro de 2015, com a queixa de gravidez psicológica; P02, 21 anos, atendida em novembro de 2015 , com a queixa de depressão

\section{Maria Lúcia Mantovanelli Ortolan e Maíra Bonafé Sei}

e dificuldades no namoro; P03, 30 anos, atendida em novembro de 2015, com a queixa de perda gestacional (aborto); P04, 62 anos, atendida em outubro de 2015, queixando-se de problemas financeiros; P05, 42 anos, atendida em setembro de 2015 , com queixas de depressão e processo de divórcio; P06, 52 anos, atendida em setembro de 2015, queixando-se de brigas no casamento.

\section{INSTRUMENTO}

O instrumento utilizado para a coleta de dados foi uma entrevista semiestruturada com um roteiro de perguntas. As perguntas estruturadas foram: (a) Por que procurou o Plantão Psicológico?; (b) O Plantão Psicológico o(a) ajudou?; (c) 0 que achou da postura do plantonista?; e (d) 0 que mudaria no serviço?. As entrevistas foram todas gravadas e transcritas na íntegra.

\section{PROCEDIMENTOS}

\section{Da coleta e registro de dados}

As entrevistas estruturadas foram realizadas ao longo dos meses de dezembro de 2016 e janeiro de 2017, de forma individual. No início da entrevista, foi explicado o objetivo da pesquisa e solicitada a assinatura do Termo de Consentimento Livre e Esclarecido e do Termo de Gravação de Voz. Foi ressaltada a manutenção do sigilo das informações fornecidas e a liberdade que o participante tinha de interromper a entrevista quando quiser. Cada entrevista teve duração de aproximadamente 15 minutos, sendo os dados transcritos na íntegra a partir da gravação de voz, constando assim todo o material de análise. Os dados que se colhem em entrevistas abertas nas pesquisas qualitativas são perspectivas dos usuários, que são consideradas não somente meras opiniões, mas assumem estatuto de experiência vivida (Barra, 2012), legitimando manter as falas dos participantes na íntegra, de maneira ilustrativa, sendo esse modo de coleta de dados, em pesquisas qualitativas em Psicologia, o mais próximo de uma verdadeira avaliação de um serviço.

\section{De organização, tratamento e análise de dados}

Para a transcrição das entrevistas, foi atribuído um número para cada participante. Para realizar a análise dos dados, a técnica de análise de conteúdo (Bardin, 2011) foi utilizada, na qual foram realizadas as etapas sequenciais de pré-análise, exploração do material ou codificação e tratamento dos resultados (inferência e interpretação). Os dados foram analisados a partir das quatro perguntas norteadoras. A partir das respostas dadas a essas questões, 


\section{INTERACÃO EM LF PSICOLOGIA}

a interpretação do que se manifestou nos discursos dos participantes foi organizada em categorias temáticas, possibilitando a discussão teórica acerca desse material, mas também respeitando a diversidade e singularidade das experiências relatadas, por isso a escolha de manter, ao longo da exposição dos resultados e das análises, as falas na íntegra dos usuários (Barra, 2012). Para uma melhor exposição dos dados, cada categoria foi analisada e interpretada em um subtópico próprio, nas seções de resultados e discussão.

\section{RESULTADOS}

A transcrição na íntegra das entrevistas e a análise de seu conteúdo possibilitaram quatro grandes blocos de análise, baseados nas perguntas norteadoras da entrevista. A partir de cada bloco foram criadas categorias, totalizando oito categorias de análise. Assim, optou-se por apresentar os resultados de acordo com os blocos de análise e suas respectivas categorias. As falas das participantes foram apresentadas ao longo dos resultados a fim de ilustrar as categorias citadas.

\section{I - POR QUE PROCUROU O PLANTÃO?}

No discurso das participantes, ao se perguntar a respeito da procura pelo plantão, foram encontradas duas categorias de análise:

a) o caráter emergencial e a necessidade da fala: abrangeu-se aqui o caráter emergencial do serviço de plantão psicológico: "eu já tenho uma inscrição lá [na fila de espera para a psicoterapia individual do serviço-escola], mas eu fui por conta de uma emergência" (P04), e a necessidade de conversar e falar sobre seus problemas, presente no discurso das participantes, juntamente com o "sentir-se sozinha" e sem ninguém para conversar, o que encorajava as participantes a irem ao plantão. Observou-se que as participantes preferem o serviço de plantão por conta de seu caráter emergencial, de atendimento rápido: "eu estava bem mal e aí eu procurei ajuda psicológica, porque me informaram que seria imediato o atendimento, então eu vim aqui" (P02). Uma paciente tentou uma ajuda psicológica no CAPS, todavia preferiu ir até o serviço-escola, pois soube que o plantão era mais rápido: "eu tinha passado no CAPS, lá ia demorar muito, acho que ia demorar três meses para fazer uma consulta" (P05).

Outro motivo de procura presente nas falas é em um sentido de desabafar, de ter com quem conversar sobre a angústia: "eu acabei me conscientizando de que eu deveria vir e deveria conversar com algum profissional" (P05); "eu fui pedir um socorro, porque eu não tinha para quem eu falar" (P04); "eu vim aqui só para conversar [...] porque eu não queria ficar sozinha em casa” (P03).

b) Expectativas de um serviço psicológico: aqui se englobou discursos das participantes sobre a duração do atendimento de plantão e seu caráter de encontro único e o quanto essa modalidade lhes é nova e estranha, já que iam à clínica com uma expectativa de psicoterapia individual semanal. As participantes verbalizam que gostariam de continuar aquele atendimento, manifestando um desejo de vir para um segundo encontro, pelo menos.

$\mathrm{O}$ que foi analisado aqui diz respeito ao desconhecimento e à imaginação da população sobre o serviço psicológico: "na verdade, eu nunca tinha frequentado um plantão psicológico, na verdade eu nem sabia que existia plantão, pensei que psicólogo você ligava, agendava e comparecia" (P02) Os usuários de demanda espontânea, principalmente, têm uma expectativa sobre o que seria o plantão psicológico: "eu queria na verdade atendimento com alguma psicóloga” (P06), tendo em vista que o serviço-escola de Psicologia na universidade é pautado em atendimentos feitos por alunos de graduação, e não necessariamente por profissionais formados. Uma participante achou que o serviço de plantão seria uma pré-avaliação, para que então ela entrasse em uma fila de espera e fosse chamada para o atendimento, semelhante à modalidade de triagem, por exemplo.

Percebe-se, ao longo das entrevistas, que as participantes chegam ao serviço com a concepção de que um tratamento longo (psicoterapia semanal individual) seria melhor do que o plantão psicológico, em modalidade de um encontro único: "[preciso da psicoterapia individual semanalmente] porque são muitos problemas para pouco tempo [...] eu tenho um problema e tenho ciência disso. Preciso de um tratamento a longo prazo" (P02).

\section{II- O PLANTÃO TE AJUDOU?}

Das seis participantes, duas entenderam que o plantão não as ajudou, na medida em que não correspondeu às expectativas delas. Uma participante disse que ajudou no momento, todavia aquele atendimento não Ihe foi suficiente, querendo dar continuidade em uma psicoterapia individual semanal.

Diante dessa segunda pergunta norteadora, foram encontradas duas categorias de análise:

a) Acolhimento: aqui se concentrou como o bom acolhimento, na visão das participantes, foi já uma ajuda do serviço: "eu fui tratada muito bem na parte da conversa [...] me entendeu" (P01); "eu estava muito perturbada no momento, eu conversei bastante e consegui me estabilizar" (P02).

b) Efeitos do encontro: esta categoria contempla as 


\section{MI* INTERACÃO EM LF PSICOLOGIA}

intervenções do plantonista feitas no atendimento que foram trazidas pelas participantes: "ela conversou bastante comigo, me deu conselhos" (P01); "ela ia me apresentando os fatos, correlacionando as coisas que eu estava passando naquele momento com coisas que poderiam estar relacionadas intimamente com a minha infância" (P02). Esta categoria agrega também a questão da dimensão dos problemas trazidos pelas participantes e como a demanda foi sendo esclarecida durante o encontro (clarificação da demanda): "então ela me entendeu e ela conseguiu passar para mim que não era aquilo que minha cabeça estava imaginando" (P01); "eu comecei a refletir e me pareceu mais óbvio" (P02); "não era tão desesperador como eu plantava" (P04). A responsabilização do sujeito em plantão também foi tratada como um efeito do encontro: "comecei a perceber, eu fui me colocando na situação" (P04), assim como a catarse/alívio proporcionado pela fala: "[o plantão] conseguiu tirar aquilo de dentro de mim [...] foi bom porque eu pude falar, poder falar, porque a gente fica cheio de sentimento, não consegue descarregar" (P03).

\section{III - 0 QUE ACHOU DA POSTURA DO PLANTONISTA?}

No discurso das participantes, quando perguntado a respeito da postura do plantonista, foram encontradas duas categorias de análise:

a) Competências do Plantonista: aqui as participantes ressaltaram o caráter profissional do atendimento, exaltando o atendimento feito por uma plantonista já psicóloga formada (assessora especial do serviço-escola da universidade), ao invés de um estudante de psicologia. Algumas competências foram atribuídas à plantonista, tais como ser empática, esclarecedora e consoladora.

b) Vínculo terapêutico na instituição: esta categoria diz respeito ao fato de que nenhuma das participantes lembrava o nome da plantonista, todavia tinham o desejo de fazer psicoterapia com a mesma pessoa: "eu gostaria de continuar sendo atendida por ela, inclusive. Não lembro o nome da pessoa" (P04); "eu achei ela uma boa profissional, tanto que depois eu até queria voltar a falar com ela” (P05).

\section{IV - O QUE MUDARIA NO SERVIÇO?}

No discurso das participantes, ao se questionar o que mudariam no serviço de plantão, foram encontradas duas categorias de análise:

a) Pontos positivos do serviço: vários elogios foram feitos ao serviço - consulta completa e rapidez para ser atendido: "eu achei muito válido mesmo, porque, assim, é uma consulta bem completa, até mais completa do que algumas consultas particulares que se faz por aí" (P05); "eu fui atendida bem rápida, não demorei, foi no mesmo dia" (P02). 0 plantão foi comparado pelas participantes com outros serviços de saúde pública, exaltando o plantão, dando reconhecimento ao viés acadêmico existente, por se tratar de um serviço-escola: "geralmente as pessoas falam muito mal dos atendimentos públicos e eu não achei nada disso, achei um atendimento ótimo" (P05); "o estudo de vocês já faz com que vocês nos compreendam, realmente compreendam as pessoas" (P01). As participantes relataram que já recomendaram o serviço de plantão a outras pessoas e já ouviram boas recomendações desse serviço: "e passei para várias pessoas o atendimento" (P04); "eu já conversei com várias pessoas também que já passaram por aqui, que aqui é um dos melhores lugares para fazer o tratamento psicológico" (P01).

b) Pontos a serem melhorados: as participantes apontaram como sugestão a expansão do serviço (mais dias e horários de atendimento, mais profissionais e mais recursos do governo para subsidiar isso). Ainda sugeriram que seja feita uma melhor divulgação do serviço, pois acham que poucas pessoas sabem que há esse atendimento na universidade.

\section{DISCUSSÃO}

Tendo como início de discussão a categoria Expectativas de um serviço psicológico, as pesquisas na área de representação social em relação aos serviços de Psicologia (Caldas, Silva, Böing, Crepaldi, \& Custódio, 2013; Gondim \& Tatagiba, 2016; Oliveira \& Menezes, 2015) argumentam que, a despeito da Psicologia já ter sido consolidada quanto ciência e profissão no Brasil há mais de 40 anos, ainda não há clareza da população quanto às atividades feitas por um psicólogo. O levantamento a respeito do imaginário coletivo e representação social da população em relação aos serviços psicológicos é de grande importância para que a Psicologia se produza conforme as demandas dos usuários de seu serviço. Pensa-se, assim, em uma psicologia muito mais construtiva e singular e menos impositiva de modelos de existência, com abertura para construção de uma prática clínica mais pertinente (Santana, Lima \& Morato, 2001).

Ao mesmo tempo em que as participantes desta pesquisa revelam a sua vontade em ter um atendimento de psicoterapia individual semanalmente (e aqui se fala de um pensamento quase que engessado de que a psicologia se constitui de terapias a longo prazo), elas pontuam as qualidades do serviço de plantão: seu caráter emergencial e o lugar da escuta e da fala, ressaltando o papel do encontro, da conversa, do ter com quem falar. Desse modo, o plantão psicológico pode ser uma modalidade que venha somar ao imaginário e representação do serviço em saúde mental e 


\section{INTERACÃO EM LF PSICOLOGIA}

ainda contribuir a compor novas práticas da Psicologia em uma perspectiva mais singular e construtiva.

$\mathrm{Na}$ categoria de análise caráter emergencial e a necessidade da fala, observa-se a importância de um espaço para a fala, indicando a pertinência de dispositivos simples de encontro. Em outras pesquisas de avaliação dos serviços de saúde mental, um Plantão Comunitário (Coin-Carvalho \& Ostronoff, 2014) e um Plantão Institucional (Lerner, Fonseca, Sayão, \& Machado, 2014) também retratam a necessidade de instaurar espaços de fala e escuta. 0 plantonista, análogo ao analista, proposto por Lacan (1958/1998), é "a quem se fala e a quem se fala livremente [...] simplesmente toma o caminho de ouvir e não de auscultar a resistência, a tensão [...] o que escuta é por ouvir" (p. 622). Quando o plantonista se põe nessa posição de escuta ativa (Gonçalves, Farinha, \& Goto, 2016) é quando o sujeito emerge no usuário e este pode, então, falar da sua experiência, contar sua narrativa, posicionar-se em sua própria história.

O serviço de plantão psicológico, em sua modalidade de atendimentos únicos, tem a intenção de potencializar o encontro e promover reflexão e responsabilização do sujeito perante o seu sofrimento, o que se retrata na categoria de análise Efeitos do encontro. Na medida em que se oferta um espaço para que o sujeito fale sobre seu sofrimento, pode-se promover um reposicionamento do sujeito diante das questões queixadas por ele: "ao oferecermos esse espaço de escuta, a queixa pode deslizar para a implicação do sujeito na produção de um saber que lhe seja mais próprio" (Lerner et al., 2014, p. 201).

Ainda na categoria Efeitos do encontro, analisa-se a questão da clarificação da demanda. As participantes relatavam que em plantão conseguiam dimensionar suas queixas, percebê-las ou com uma magnitude menor, ou simplesmente enxergar outras perspectivas para o mesmo problema. Esse é mais um dos benefícios ao sujeito proporcionado pela oferta de escuta e possibilidade de fala. Esse desnudamento da queixa em plantão faz entender "a queixa como um 'querer dizer' - como uma produção discursiva que reflete a alienação do sujeito" (Lerner et al., 2014 , p. 201) em relação às múltiplas determinações das condições que lhe acometem. Desse modo, os efeitos do atendimento em plantão psicológico são trazidos pelas participantes como a clarificação da demanda e assim uma possibilidade de responsabilização do sujeito frente à sua queixa. A clarificação e responsabilização são elementos que promovem, assim, o empoderamento deste para que possa, então, almejar ser protagonista de sua própria história, tornando o usuário mais autônomo frente a sua vida (CoinCarvalho \& Ostronoff, 2014; Campos \& Daltro, 2015).

A fim de proporcionar reflexões mais profundas e um posicionamento mais crítico em relação aos achados nas pesquisas, observa-se, nas categorias Expectativas de um serviço psicológico, Caráter emergencial e a necessidade da fala e Efeitos do encontro, que o atendimento psicológico em forma de plantão tem um caráter desmistitificador do que é e do que pode ser a atuação da Psicologia. Nesse sentido, propõe-se encontros potentes visando não reforçar um cuidado assistencialista e dependente; os participantes indicaram também a necessidade de fala do usuário que não se comporta em filas longas de espera para atendimento em psicologia, visibilizando o caráter emergencial das demandas psicológicas e o plantão como modalidade que acolhe essa demanda, a partir do momento em que não se engessa em agendamentos e filas; e as falas contidas nessas categorias até agora discutidas também apontam para o potencial de um encontro, que vislumbra a possibilidade de cuidado em saúde, principalmente em saúde mental, de forma mais humanizada, não patologizante e não medicalizante.

A categoria de análise Acolhimento aqui será analisada tendo em vista as diretrizes da Atenção Básica de Saúde. Uma vez que o plantão psicológico muitas vezes se torna porta de entrada do usuário para outros serviços psicológicos, entende-se aqui o plantão como um dispositivo da atenção primária. 0 acolhimento é uma das diretrizes de maior relevância ética e política do SUS (Ministério da Saúde, 2013)

As participantes da pesquisa julgaram ter um bom acolhimento no serviço do plantão: "eu fui bem tratada [...] ela me entendeu [...] conversou bastante comigo [...] eu consegui me abrir com ela" (P01); "eu conversei bastante [...] soube conversar comigo" (P02); "consegui falar, ela me deu atenção, geralmente as pessoas não dão muita importância para o que a gente tá sentindo [...] ela foi muito simpática comigo" (P.03). As falas das participantes corroboram na definição de acolhimento, na qual acolher diz respeito ao dar ouvidos, ao estar com um outro, estar perto de um outro, em uma ação de aproximação, de inclusão (Ministério da Saúde, 2013).

Os serviços de saúde, principalmente na saúde mental, não podem perder o caráter humano do acolhimento. 0 plantão psicológico ativa a potência do encontro e a importância de um bom acolhimento nesse encontro. A escuta no plantão não pode ser anestesiada, o plantonista não pode produzir indiferença diante do sujeito que sofre, seria ingenuidade achar que assim se estaria protegido do sofrimento (Ministério da Saúde, 2013). Faz-se necessário manter 0 acolhimento nos moldes apontados pelas participantes, uma vez que isso fomenta o laço entre sujeito e plantonista, propiciando ao sujeito forças de invenção e de resistência para lidar com o seu sofrimento.

A categoria de análise Competências profissionais se faz 
intimamente ligada com a questão do acolhimento de um serviço de saúde. As participantes apontaram que as plantonistas foram empáticas, esclarecedoras e consoladoras. No trabalho de Vieira e Anjos (2013), com estudantes plantonistas na UFPA, os autores entenderam que há um movimento de se tornar plantonista, podendo elencar alguns aspectos pertinentes à formação do plantonista, tais como a experiência clínica do estudante, no sentido da compreensão da experiência vivida pelo usuário e envolvimento ativo na relação terapêutica. Os autores consideram ao final que a experimentação seria o melhor preparo para esses estudantes a tornarem-se plantonistas, uma vez que o domínio técnico se mostra insuficiente na atuação dessa prática.

A última categoria de análise discutida é Vínculo terapêutico com a instituição. As participantes não lembravam o nome da plantonista que lhe atenderam, o que abre espaço para discutir o tipo de vínculo terapêutico existente em práticas institucionais. Nota-se, com isso, um vínculo por vezes maior com a instituição do que com a figura do plantonista. A despeito disso, mesmo sem recordação do nome do profissional, verbalizam o desejo de ser novamente atendidas pelas mesmas pessoas, com elogios ao acolhimento recebido, indicando, então, que algum tipo de ligação foi feita no encontro único em plantão.

A respeito do vínculo terapêutico em plantão psicológico, Alves e Morales (2009) constataram que essa é uma modalidade que pode propiciar sim um vínculo entre usuário e plantonista, mesmo em seu espaço curto de tempo. Argumentam que "não se pode prever o tempo necessário para que tal ligação aconteça, uma vez que cada cliente estabelece uma relação única com o terapeuta" (Alves \& Morales, 2009, p. 1). 0 estabelecimento desse tipo de vínculo é essencial para que o sujeito se sinta empoderado a protagonizar sua vida. Para que esse vínculo aconteça, o acolhimento e, consequentemente, as competências do plantonista são determinantes, pois uma vez que o usuário percebe que naquele encontro há um tipo de cuidado e apoio, ele então permite a fala, pode se sentir protegido, o que pode dar-lhe um maior controle frente às coisas que lhe acomete.

Tendo exposto as categorias temáticas Expectativas de um serviço psicológico, Caráter emergencial e a necessidade da fala, Efeitos do encontro, Acolhimento, Competências profissionais e Vínculo terapêutico com a instituição, é necessário, além de compreender o significado destas, como feito acima, esboçar a sua operacionalização enquanto técnica, e, consequentemente, seus desdobramentos no ordenamento do trabalho instituído, suas articulações e tensionamentos teóricos. A respeito da operacionalização dessas categorias enquanto técnica, as categorias de
Acolhimento, Caráter emergencial e a necessidade de fala e Competências profissionais merecem destaque.

Visualizar a dimensão técnica do acolhimento requer entender que o exercer de um bom acolhimento é resultado de outras dimensões do cuidado que estão ocultas: "o acolhimento demanda uma escuta qualificada que deve basear-se em princípios de humanização, solidariedade, respeito, compromisso, julgamento, aceitação, liberdade e responsabilidade" (Cardoso, 2014, p.11). A operacionalização do conceito de acolhimento, exposto isso, fica complexa. Algumas abordagens teóricas da Psicologia, como a Abordagem Centrada na Pessoa, dão alguns norteadores de subsídio para que o terapeuta, aqui no caso plantonista, possa desenvolver um acolhimento efetivo em sua prática. Rogers (1974) aponta, então, para as atitudes psicológicas facilitadoras, tais como o sentimento de consideração positiva incondicional, sensação de compreensão empática sobre o relato do usuário e atitude de congruência. Todas essas atitudes foram citadas por Scorsolini-Comin (2014) ao teorizar a prática de plantão psicológica em um terreiro de umbanda.

O fato dos usuários buscarem o plantão psicológico em situações que para eles se configuram como uma emergência diz respeito ao lugar da urgência subjetiva desse jeito. A atuação do psicológico em situações emergenciais tem sido delineada por alguns estudos (Ministério da Saúde, 2006; Scremin, Ávila, \& Branco, 2009; Silva, et al., 2013; Trindade \& Serpa, 2013), que servem de arcabouço teórico para pensar a técnica envolvendo o plantonista, que também se põe em trabalho frente à urgência subjetiva daquele sujeito. De modo geral, as intervenções propostas a esses casos direcionam a uma "reabilitação do indivíduo, procurando exercer influência no funcionamento psicológico, facilitando as condições necessárias para que este funcionamento seja mais adaptativo, de acordo com a situação" (Almondes, Sales, \& Meira, 2016, p. 449).

Algumas competências do plantonista foram mencionadas pelas entrevistadas. Na medida em que foram competências que trouxeram uma boa avalição ao atendimento e ao serviço, problematização à técnica envolta dessas competências, vislumbrando um acrescimento na formação de psicólogo, por exemplo, mediante a experiência de prática de plantão. Wojciekowski e Pizzinato (2014), com o objetivo de compreender as relações de ensino/ aprendizagem de práticas psicológicas, por meio da vivência dos estudantes em estágios básicos, entendeu que é por meio da prática, da experimentação do estudante, que se teria a chance de "romper com as práticas ditas 'tradicionais' e ao mesmo tempo a inventar, criar, experimentar, conhecer, ousar novos saberes" (Wojciekowski, \&Pizzinato, 2014, p. 6) 


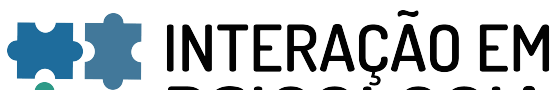 ET PSICOLOGIA}

entendendo que assim se movimentaria a "formação em Psicologia para além das formas já hegemônicas na atual formação generalista" (Wojciekowski, \& Pizzinato, 2014, p.6). Como já exposto, o plantão psicológico ofertado no serviçoescola caracteriza-se como um projeto de extensão da universidade, ficando a critério do estudante aderir ou não. Uma vez que se demonstra aqui algumas competências encontrada em plantonistas, e tendo como norte de aprendizagem o que Wojciekowski e Pizzinato (2014) colocam, pela experimentação, pelo "aprender fazendo", farse-ia muito interessante ter o plantão psicológico como uma disciplina ou estágio obrigatório na grade curricular do estudante de psicologia da referida universidade.

Os estudos que objetivam compreender a visão dos usuários de serviços de saúde são importantes para conhecer a opinião e as expectativas das pessoas que recebem atendimento, sendo esses dados elementos importantes na avaliação e aprimoramento desses serviços (Silva, et al., 2016). De modo geral, este estudo evidenciou uma satisfação dos participantes principalmente em relação às variáveis: acolhimento por parte do plantonista, rapidez no atendimento e bem-estar proporcionado pela conversa tida no plantão. Os participantes ainda elencaram como aspectos negativos poucos horários de atendimento - reivindicação essa que já foi atendida. $\mathrm{Na}$ época das participantes, o serviço só funcionava um dia da semana, atualmente ele é ofertado todos os dias.

Acredita-se que os dados obtidos são importantes no que se refere à atenção à saúde, pois são indicadores que conduzem os gestores dos serviços de saúde para melhorias na resolutividade do serviço e na satisfação das necessidades singulares dos usuários. Aponta-se aqui como limitação deste estudo o pequeno número de participantes entrevistados. Sugere-se que pesquisas de caráter de followup e de avaliação de serviço sejam feitas, principalmente em equipamentos da rede de saúde mental e serviços-escola de Psicologia, para que os gestores e profissionais em saúde possam estabelecer prioridades e programar ações na atenção à sua saúde de maneira apropriada e específica para população atendida.

\section{DECLARAÇ̃̃O DE FINANCIAMENTO}

A pesquisa relatada no manuscrito foi financiada pela bolsa de iniciação científica CNPq da primeira autora.

\section{DECLARAÇÃO DA CONTRIBUIÇÃO DOS AUTORES}

Certificamos que todos os autores participaram
Maria Lúcia Mantovanelli Ortolan e Maíra Bonafé Sei

suficientemente do trabalho para tornar pública sua responsabilidade pelo conteúdo. M.L.M.O. foi responsável pelo delineamento, coleta de dados e escrita do artigo e M.B.S. foi responsável pela orientação da pesquisa, revisão e edição do artigo.

\section{DECLARAÇÃO DE CONFLITOS DE INTERESSE}

Os autores declaram que não há conflitos de interesse no manuscrito submetido.

\section{REFERÊNCIAS}

Almeida, F., \& Melo-Silva, L. (2006). Avaliação de um Serviço de Orientação Profissional: A Perspectiva de Ex-Usuários. Revista Brasileira de Orientação Profissional, 7(2), 81-102. Recuperado em 08 abr 2018, de http://pepsic.bvsalud.org/ pdf/rbop/v7n2/v7n2a08.pdf

Almondes, K.; Sales, E.; Meira, M. (2016). Serviço de Psicologia no SAMU: Campo de Atuação em Desenvolvimento. Psicologia Ciência e Profissão, 36(2), 449-457. http://dx.doi.org/10.1590/1982-3703000992014

Amorim, F. B. T., Andrade, A. B. D., \& Branco, P. C. C. (2015). Plantão psicológico como estratégia de clínica ampliada na atenção básica em saúde. Contextos Clínicos, 8(2), 141-152. http://dx.doi.org/10.4013/ctc.2015.82.03

Alves, R. C. R., \& Morales, G. (2009). Vínculo terapêutico no plantão psicológico: uma discussão sob a perspectiva da análise do comportamento. Revista de Psicologia, 2, 1-3. Recuperado em 07 nov 2017, de https:// psicologianpa.wordpress.com/2012/05/24/e3-46plantao-psicologico-sob-o-enfoque-da-analise-docomportamento/

Aun, H. A., Morato, H. T. P., Noguchi, N. F. D. C., \& Nunes, A. P. (2006). Transgressão e juventude encarcerada: outras versões a partir do plantão psicológico em unidades de internação da FEBEM/SP. Imaginário, 12(12), 35-53. Recuperado em 07 nov 2017, de http://pepsic.bvsalud.org/ scielo.php?script=sci_arttext\&pid=S1413666 X2006000100003\&lng=pt\&nrm=iso

Bardin, L. (2011). Análise de conteúdo. Lisboa: Editora Edições 70.

Barra, T. Y. D. L. (2012). Experiência de psicólogos em plantão psicológico: introduzindo o atendimento a famílias. Tese de Doutorado em Psicologia, Pontifícia Universidade Católica de São Paulo, São Paulo.

Braga, T. B. M., Mosqueira, S. M., \& Morato, H. T. P. (2012). Cartografia clínica em plantão psicológico: investigação interventiva num projeto de atenção psicológica em distrito policial. Temas em Psicologia, 20(2), 555-570. http://dx.doi.org/10.9788/TP2012.2-20 


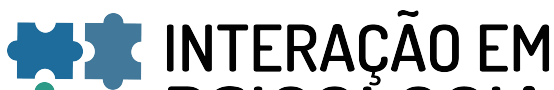 ET PSICOLOGIA}

Caldas, D. B., Silva, A. L. R. D., Böing, E., Crepaldi, M. A., \& Custódio, Z. A. D. O. (2013). Atendimento psicológico no pré-natal de alto-risco: a construção de um serviço. Psicologia Hospitalar, 11(1), 66-87. Recuperado em 07 nov 2017, de http://pepsic.bvsalud.org/pdf/ph/v11n1/ v11n1a05.pdf

Campos, A. F., \& Daltro, M. (2015). A clínica ampliada no enfoque da gestalt-terapia: um relato de experiência em supervisão de estágio. Revista Psicologia, Diversidade e Saúde, 4(1), 59-68. http://dx.doi.org/10.17267/23173394rpds.v4i1.743

Campos, A. P. Sá, \& Cury, V. E. (2009). Atenção psicológica clínica: encontros terapêuticos com crianças em uma creche. Paidéia (Ribeirão Preto), 19(42), 115-121. http:// dx.doi.org/10.1590/S0103-863X2009000100014

Cardoso, S. D. M. (2014). Relato de experiência sobre o acolhimento em uma unidade de saúde mental para crianças e adolescente. Monografia de Especialização em Linhas de Cuidado em Enfermagem, Universidade Federal de Santa Catarina, Santa Catarina

Coin-Carvalho, J. E., \& Ostronoff, V. H. (2014). Cuidado e transformação social: avaliação da implantação do plantão comunitário no Complexo da Funerária. Estudos de Psicologia, 19(2), 89-156. http://dx.doi.org/10.1590/ S1413-294X2014000200006

Farinha, M. G., \& Souza, T. M. C. (2016). Plantão psicológico na delegacia da mulher: experiência de atendimento sócio-clínico. Revista da SPAGESP, 17(1), 65-79. Recuperado em 07 nov 2017, de http://pepsic.bvsalud.org/ pdf/rspagesp/v17n1/v17n1a07.pdf

French, F., Hiebert, B. \& Bezanzon, L. (1994). Introduction: And emerging evaluation model for changing times. Canadian Journal of counseling/Revue canadienne de counseling, 28(4), 261-269. Recuperado em 08 abr 2018, de http://cjcrcc.ucalgary.ca/cjc/index.php/rcc/article/view/20/979

Furigo, R. C. P. L.; Sampedro, K. M.; Zanelato, L. S.; Foloni, R. F.; Ballalai, R. C.; Ormrod, T. (2008). Plantão psicológico: uma prática que se consolida. Boletim de Psicologia, 58(129), 185-192. Recuperado em 07 nov 2017, de http:// pepsic.bvsalud.org/pdf/bolpsi/v58n129/v58n129a06.pdf

Gonçalves, L. D. O., Farinha, M. G., \& Goto, T. A. (2016). Plantão psicológico em unidade básica de saúde: atendimento em abordagem humanista-fenomenológica. Revista da Abordagem Gestáltica, 22(2), 225-232. Recuperado em 07 nov 2017, de http://pepsic.bvsalud.org/ $\mathrm{pdf} / \mathrm{rag} / \mathrm{v} 22 \mathrm{n} 2 / \mathrm{v} 22 \mathrm{n} 2 \mathrm{a} 15 . \mathrm{pdf}$

Gondim, D. S. M., \& Tatagiba, V. M. R. O. (2016). Conhecer para otimizar o fazer: sobre a representação social da psicologia no hospital. Sinais, 19, 71-86. https://doi.org/ $10.25067 /$ s.v1i19.11134
Maria Lúcia Mantovanelli Ortolan e Maíra Bonafé Sei

Guedes, M. (2006). Intervenções psicossociais no sistema carcerário feminino. Psicologia ciência e profissão, 26(4), 559-569. 98932006000400004

Hoffmann, M. C. C. L., Santos, D. N., \& Mota, E. L. A. (2008). Caracterização dos usuários e dos serviços prestados por Centros de Atenção Psicossocial Infanto-Juvenil. Cadernos de saúde pública, 24(3), 633-642. http:// dx.doi.org/10.1590/S0102-311X2008000300017

Lacan, J. (1998). A direção do tratamento e os princípios de seu poder. In: Lacan, J. Escritos (pp. 591-652). Rio de Janeiro: Jorge Zahar. (Original publicado em 1958).

Laguardia, J. ; Domingues, C. M. A.; Carvalho, C.; Lauerman, C. R.; Macário, E.; Glatt, R. (2004). Sistema de informação de agravos de notificação em saúde (Sinan): desafios no desenvolvimento de um sistema de informação em saúde. Epidemiologia e Serviços de Saúde, 13(3), 135-146. http://dx.doi.org/10.5123/S1679-49742004000300002

Lerner, A. B. C., Fonseca, P. F., Sayão, Y., \& Machado, A. M. (2014). Plantão Institucional: uma modalidade de intervenção face ao mal-estar contemporâneo na educação. Estilos da clínica, 19(1), 199-208. http:// dx.doi.org/10.11606/issn.1981-1624.v19i1p199-208

Minayo, M.C.S. (2004). o desafio do conhecimento: pesquisa qualitativa em saúde. $8^{\mathrm{a}}$ ed - São Paulo: Hucitec.

Ministério da Saúde. (2006). Política Nacional de Atenção às Urgências (3a ed.). Brasília, DF: Ministério da Saúde.

Ministério da Saúde. Secretaria de Atenção à Saúde. Departamento de Atenção Básica. (2013). Acolhimento à demanda espontânea. (Cadernos de Atenção Básica; n. 28, v. 1) Brasília: Ministério da Saúde.

Mota, S. T., \& Goto, T. A. (2009). Plantão psicológico no CRAS em Poços de Caldas. Fractal: Revista de Psicologia, 21(3), 521-530. http://dx.doi.org/10.1590/S198402922009000300007

Mozena, H. (2009). Plantão Psicológico: Estudo fenomenológico em um serviço de assistência judiciária. Dissertação de mestrado, Pontifícia Universidade de Campinas, Campinas.

Oliveira, M. L., \& Menezes, J. E. (2015). Do hospício ao centro de atenção psicossocial em Alagoinhas/Bahia: um estudo das representações sociais e familiares. Diálogos Possíveis, 14(2), 114-131. Recuperado em 07 nov 2017, de http://www.faculdadesocial.edu.br/revistas/index.php/ dialogospossiveis/article/view/316/253

Pan, M., Zonta, G. A., \& Tovar, A. (2015). Plantão Institucional: relato de experiência de uma intervenção psicológica na UFPR. Psicologia em Estudo, 20(4), 555-562. http:// dx.doi.org/10.4025/psicolestud.v20i4.27594 


\section{MI* INTERACÃO EM LF PSICOLOGIA}

Ramos, M. T. (2012). Plantão psicológico em instituição de longa permanência para idosos: um estudo fenomenológico. Dissertação de mestrado, Pontifícia Universidade Católica de Campinas, Campinas.

Rasera, E. F., \& Issa, C. L. G. (2007). A atuação do psicólogo em ONG/AIDS. Psicologia: Ciência e profissão, 27(3), 566575. 98932007000300015

Rogers, C. R. (1974). A terapia centrada no paciente. Lisboa, Portugal: Moraes.

Rosario, Â. B., \& Neto, F. K. (2016). Plantão psicológico em uma clínica-escola de psicologia: saúde pública e psicanálise. A peste: Revista de Psicanálise e Sociedade e Filosofia, 7(1), 37-48. http://dx.doi.org/10.5546/ peste.v7i1.30463

Santana, A. M., Lima, A. O., \& Morato, H. T. P. (2001). A experiência do usuário como via de re-significação das práticas psicológicas na rede pública da saúde. Revista Interlocuções, 2, 15-28.

Santeiro, T. V. (2008). Psicoterapia breve psicodinâmica preventiva: pesquisa exploratória de resultados e acompanhamento. Psicologia em Estudo, 13(4), 761-770. http://dx.doi.org/10.1590/S1413-73722008000400014

Schimidt, M. L. S. (2006). Continuidade e ruptura: Interpretação da história do Serviço de Aconselhamento Psicológico do Instituto de Psicologia da USP. Mnemosine, 2(2), 3-32. Recuperado em 07 nov 2017, de http:// www.mnemosine.com.br/ojs/index.php/mnemosine/ article/view/88/pdf_74

Scorsolini-Comin, F. (2014). Plantão psicológico centrado na pessoa: Intervenção etnopsicológica em terreiro de umbanda. Temas em Psicologia, 22(4), 885-899. http:// dx.doi.org/10.9788/TP2014.4-16

Scorsolini-Comin, F. (2015). Plantão psicológico e o cuidado na urgência: panorama de pesquisas e intervenções. Psico-USF, 20(1), 163-173. http://dx.doi.org/ 10.1590/1413-82712015200115

Scremin, S. M., Ávila, R. C. D., \& Branco, C. J. (2009). Alcance e limites do serviço de psicologia do hospital de pronto socorro de Canoas-deputado Nelson Marchezan. Revista da SBPH, 12(1), 57-69. Recuperado em 07 nov 2017, de http://pepsic.bvsalud.org/pdf/rsbph/v12n1/v12n1a05.pdf

Silva, A. F. S., Bastos, A. S., \& Silva, F. O. (2017). Experiências educativas no Centro Juvenil de Ciência e Cultura: um espaço não formal de aprendizagem. Revista Educação e Emancipação, 10(2), 165-184. http://dx.doi.org/ 10.18764/2358-4319.v10n2p165-184
Silva, T. L. G., et al. (2013). Primeiros socorros psicológicos: relato de intervenção em Santa Maria. Revista Brasileira de Psicoterapia, 15(1), 93-104. Recuperado em 07 nov 2017, de http://www.rbp.celg.org.br/audiencia_pdf.asp? aid2=113\&nomeArquivo=v15n1a09.pdf

Slive, A., \& Bobele, M. (2012). Walk-in counselling services: making the most of one hour. Australian and New Zealand Journal of Family Therapy, 33(1), 27-38. http://dx.doi.org/ 10.1017/aft.2012.3

Szymanski, H. (2004). Plantão psicoeducativo: novas perspectivas para a prática e pesquisa em psicologia da educação. Psicologia da Educação, 19, 169-182. Recuperado em 07 nov 2017, de http://pepsic.bvsalud.org/ pdf/psie/n19/n19a09.pdf

Trindade, M. C., \& Serpa, M. G. (2013). O papel dos psicólogos em situações de emergências e desastres. Estudos e Pesquisas em Psicologia, 13(1), 279-297. Recuperado em 07 nov 2017, de http://pepsic.bvsalud.org/pdf/epp/v13n1/ v13n1a17.pdf

Vieira, E. M., \& Boris, G. D. J. B. (2012). O plantão psicológico como possibilidade de interlocução da psicologia clínica com as políticas públicas. Estudos e Pesquisas em Psicologia, 12(3), 883-896. Recuperado em 07 nov 2017, de http://pepsic.bvsalud.org/pdf/epp/v12n3/ v12n3a10.pdf

Vieira, E. M., \& Anjos, K. P. L. (2013). Tornar-se plantonista: O fluxo de atitudes facilitadoras a partir da experiência de plantonistas iniciantes. In M. A. Tassinari, A. P. S. Cordeiro, \& W. T. Durange (Eds.), Revisitando o plantão psicológico centrado na pessoa (pp. 101-124). Curitiba, PR: CRV.

Wojciekowski, C. F., \& Pizzinato, A. (2014). Estágios Básicos: como as práticas e as Diretrizes Curriculares Nacionais repercutem na formação e atuação do Psicólogo. Psicologia Argumento, 32(79), 45-56.

Data de submissão: 08/11/2017 Primeira decisão editorial: 04/04/2018 Aceite em 23/04/2018 